\title{
Percutaneous balloon compression for primary trigeminal neuralgia in patients older than 80 years
}

\author{
Yuan-Feng Du, Qiao Gu, Ding-Bo Yang, Xiao-Qiao Dong, Quan Du, Hao Wang and Wen-Hua Yu*
}

\begin{abstract}
Background: It has been demonstrated that the incidence of trigeminal neuralgia in elderly patients is higher and thus, neurosurgeons often encounter elderly patients with this disorder. However, for those with poor basic condition, the optimal surgical treatment remains controversial. In this study, the authors aimed to evaluate the safety and efficacy of percutaneous balloon compression (PBC) for primary trigeminal neuralgia in elderly patients older than 80 years.

Methods: From September 2009 to March 2013, a total of 68 patients older than 80 years underwent PBC, and a retrospective study of the clinical data of these patients was performed.

Results: After PBC, pain relief was immediate in 66 (97.0 \%) patients, 1 (1.5\%) patient had no pain relief, and 1 (1.5\%) patient had some pain that could be controlled with medication. With a mean length of follow-up of 40.1 months, ranging from 24 to 66 months after surgery, 55 (80.9\%) patients were still pain free. Of the 11 patients with recurrence, 9 cases had mild recurrence and 2 cases suffered severe recurrence. The mean time to recurrence was 18.9 months (1-64 months). Postoperative morbidity included common side effects such as facial numbness in 66 (97.1\%) patients, masseter muscle weakness in 19 (27.9\%) patients, paresthesia in 7 (10.3\%) patients, and diplopia secondary to abducens nerve weakness in 1 (1.5\%) patient. No corneal anesthesia, subarachnoid hemorrhage, or other serious surgical complications occurred in this study.

Conclusions: In this study, the authors reviewed data on a cohort of patient older than 80 years. The PBC procedure has advantages in that it is minimally invasive, safe, effective, and could be performed under general anesthesia. This makes it an optimized choice for elderly patients.
\end{abstract}

Keywords: Trigeminal neuralgia, Percutaneous balloon compression, Elderly, Safety

\section{Background}

Trigeminal neuralgia is a disorder characterized by sharp and paroxysmal pain within the trigeminal nerve distribution. With the aging population, the proportion of elderly patients is gradually increased [1]. The etiology of trigeminal neuralgia is still controversial. Since Jannetta [2] refined and popularized microvascular decompression (MVD), it has become the first-line choice [3, 4], but it is nonetheless associated with some special risks such as cranial nerve injury, cerebellar hematoma, stroke, and death which are not

\footnotetext{
*Correspondence: d542762345@126.com

Department of neurosurgery, The Hangzhou First People's Hospital, Nanjing Medical University affiliated Hangzhou Hospital, 261 Huansha Road, Hangzhou 310000, China
}

seen with the commonly performed ablative procedures. So for the elderly patients older than 80 years, whether or not performing MVD is still controversial [5-7]. Percutaneous balloon compression $(\mathrm{PBC})$ was first described by Mullan and Lichtor [8] in 1983. Because PBC is a minimally invasive, low-cost, safe, and effective procedure and could be simply performed with the patient under general anesthesia, it has become increasingly popular around the world. It has also been reported to provide longer pain relief than the other two percutaneous proceBy now, no analysis regarding PBC for elderly patients has been reported. In this study, we aimed to evaluate the safety and efficacy of $\mathrm{PBC}$ for primary trigeminal neuralgia in elderly patients older than 80 years. 


\section{Methods \\ Patients}

In this study, all patients had been approved by the appropriate ethics and we obtained informed patient consent. From September 2009 to March 2013, a total of 73 patients older than 80 years underwent $\mathrm{PBC}$ at the Department of Neurosurgery in the Hangzhou First People's Hospital. Four patients died for other reasons and one patient was lost to follow-up, so these five patients were excluded in this study. The demographic characteristics of these 68 patients are summarized in Table 1 . The patients (38 women and 30 men) were aged between 80 and 92 years; the mean age was 84.5 years. Second combined with third division was the most common condition, affecting 29 (42.6\%) patients, followed by the third and second division in 15 (22.1\%) patients and 13 (19.1\%) patients, respectively. The right side was affected in 39 patients, while the left side in the other 29. Of these 68 patients, 28 patients had one or more prior surgical treatment. Before $\mathrm{PBC}$, all patients had received medical treatment such as carbamazepine, oxcarbazepine, gabapentin, and so on and were refractory or intolerant to the medical treatment. Prior to the surgical procedure, they also had a $\mathrm{CT}$ or MR imaging to exclude secondary trigeminal neuralgia.

Table 1 The demographic characteristics of these 68 patients

\begin{tabular}{ll}
\hline Age, year (range) & $84.5(80-92)$ \\
Sex (M:F), no & $30: 38$ \\
Disease duration, year (range) & $12.3(3-45)$ \\
Pain involvement, no (\%) & \\
V1 & $3(4.4 \%)$ \\
V2 & $13(19.1 \%)$ \\
V3 & $15(22.1 \%)$ \\
V1 + V2 & $6(8.8 \%)$ \\
V2 + V3 & $29(42.6 \%)$ \\
V1 + V2 + V3 & $2(2.9 \%)$ \\
Side affected, no (\%) & \\
Left side & $29(42.6 \%)$ \\
Right side & $39(57.4 \%)$ \\
Clinical subtypes, no (\%) & \\
Typical & $62(91.2 \%)$ \\
Atypical & $6(8.8 \%)$ \\
Previous operations, no (\%) & $28(41.2 \%)$ \\
Glycerol injection & 24 \\
MVD & 4 \\
Radiofrequency thermocoagulation & 19 \\
Alcohol blocks & 12 \\
\hline
\end{tabular}

\section{Surgical technique}

The method we used was in accordance with the technique first described by Mullan and Lichtor [8] with modification. All PBCs were performed under a short-acting general anesthesia. During operation, the heart rate, ECGs, and blood pressure of the patients were closely monitored. The patients were placed in the supine position on the operating table, with slight extension and approximately $30^{\circ}$ of rotation of the neck away from the ill side. The procedure was performed using $\mathrm{C}$-arm image intensifier fluoroscope in order to obtain lateral images and location. The entry point was positioned at about $2.5 \mathrm{~cm}$ lateral to commissure of the lips, and the other two reference points were $3 \mathrm{~cm}$ anterior to the external auditory meatus along the zygomatic arch, and $1 \mathrm{~cm}$ inferior to the pupil and. A 14-gauge needle containing a blunt obturator was advanced until it penetrated the foramen ovale under lateral fluoroscopic imaging. The blunt obturator was then withdrawn, and a no. 4 Fogarty balloon catheter with a stainless steel stylet was advanced into Meckel's cave under direct fluoroscopy. Then, the stylet was withdrawn. Under fluoroscopic control, the balloon was slowly inflated by adding undiluted contrast Omnipaque (300 mg iodine/ $\mathrm{mL}$ ) until it was proximal to the posterior fossa. Referring to the bony landmarks (clivus, sella, and petrous bones), the balloon shape and position were inspected. If necessary, the balloon was deflated and the catheter was repositioned until a pear-shaped balloon with a protrusion towards the posterior fossa was obtained. The balloon volume of this study was between 0.45 and $0.85 \mathrm{~mL}$ (depending on the individual's volume of Meckel's cave), and balloon compression time was between 3 and $8 \mathrm{~min}$. After compression, the balloon was deflated, withdrawn with the catheter. The puncture wound was compressed for about $5 \mathrm{~min}$. The total procedure usually lasted for less than $20 \mathrm{~min}$.

\section{Follow-up and effect evaluation}

Postoperative data were obtained by independent neurosurgeon by telephone or in the outpatient clinic. Four patients died for other reasons and one patient was lost to follow-up, so these five patients were excluded in this study. Assessment of result is based on Barrow Neurological Institute (BNI) pain intensity scale score (Table 2). Mild recurrence is defined as BNI pain score increased from I to II-III during the postoperative period. Severe recurrence was defined as BNI pain score increased from I to $\mathrm{IV}-\mathrm{V}$.

\section{Results}

The results of these 68 patients are summarized in Table 3. After PBC, pain relief was immediate in 66 (97.0\%) patients (BNI I), 1 (1.5\%) patient had no pain relief (BNI $\mathrm{V})$, and 1 (1.5\%) patient had some pain (BNI III) that 
Table 2 Barrow Neurological Institute (BNI) pain intensity scale score

\begin{tabular}{ll}
\hline Score & Definition \\
\hline I & No pain, no medication \\
III & Occasional pain, not requiring medication \\
IV & Some pain, adequately controlled with medication \\
V & Some pain, not adequately controlled with medication \\
\hline
\end{tabular}

could be controlled with medication. With a mean length of follow-up of 40.1 months, ranging from 24 to 66 months after surgery, 55 (80.9\%) patients were still pain free (BNI I). Of the 11 patients with recurrence, 9 cases had mild recurrence and 2 cases suffered severe recurrence. The mean time to recurrence was 18.9 months (164 months).

Postoperative morbidity was listed in Table 4. As expected, facial numbness was the most common morbidity, occurred in 66 (97.1\%) patients, but most of them could tolerate it well. Masseter muscle weakness affected 19 (27.9 \%) patients; most of them recovered within 12 months after operation. One $(1.5 \%)$ patient suffered diplopia secondary to abducens nerve weakness and recovered within 4 months. Twenty-seven (39.7\%) patients had herpes simplex after PBC, and the symptoms lasted within 2 weeks. Paresthesia occurred in $7(10.3 \%)$ patients. No corneal anesthesia, subarachnoid hemorrhage, or other serious surgical complications occurred in this study.

\section{Discussion}

Trigeminal neuralgia is a disorder which has a tendency to occur in the older patients [1], with a mean age of 51.5 years at diagnosis [9]. With the aging population, the proportion of elderly patients has gradually increased [1]. Since Jannetta [2] refined and popularized MVD, it has become the first-line choice $[3,4]$, but it is nonetheless associated with some special risks such as cranial nerve injury, cerebellar hematoma, stroke, and death which are not seen with the commonly performed ablative procedures. Many authors have reported the safety and efficacy for the elderly patients treated with MVD.

Table 3 The outcomes of the 68 patients after PBC

\begin{tabular}{lll}
\hline BNI pain score & $\begin{array}{l}\text { Immediately after } \\
\text { PBC, number of } \\
\text { patients (\%) }\end{array}$ & $\begin{array}{l}\text { During the } \\
\text { postoperative period, } \\
\text { number of patients (\%) }\end{array}$ \\
\hline I & $66(97.0)$ & $55(80.9)$ \\
III & 0 & $3(4.4)$ \\
IV & $1(1.5)$ & $7(10.3)$ \\
V & 0 & $1(1.5)$ \\
\hline
\end{tabular}

Table 4 The complications of the 68 patients after PBC

\begin{tabular}{ll}
\hline Complications & Cases (\%) \\
\hline Facial numbness & $66(97.1)$ \\
Masseter muscle weakness & $19(27.9)$ \\
Paresthesia & $7(10.3)$ \\
Diplopia & $1(1.5)$ \\
Herpes simplex & $27(39.7)$ \\
\hline
\end{tabular}

The age cutoffs range from 60 to 75 years [10-15]. So for the elderly patients older than 80 years, MVD is still controversial [5-7]. Yang et al. [15] reported outcomes on 59 patients older than 65 years, and they found that the acute pain relief after surgery was $93.2 \%$ and the recurrence rate was $8.9 \%$ with a mean length of follow-up of 42 months. Complications after surgery included headaches, nausea, and vomiting; there were no severe morbidities and mortalities. Günther et al. [11] reported the results of 112 patients older than 65 years (mean 70.35 years), the pain-free and recurrence rate were 75 and $14 \%$, respectively, with a mean length of follow-up of 90 months, and complications included hypesthesia in $6.25 \%$ of the patients, hypacusis in $5.4 \%$ of patients, and partial facial nerve palsy, complete hearing loss, and vertigo in $0.89 \%$ each. One patient suffered meningitis and cerebrospinal fluid leak [11]. In Sekula et al.'s report [14], the acute pain relief was achieved in $96 \%$ of the 25 patients older than 75 years, with an average follow-up of 44 months; $78 \%$ of the patients remained pain free. So far, several published studies [10-15] suggested that the safety and efficacy of MVD in elderly patients have no difference with the younger ones. But these studies were small sample sizes, and Sekula et al. summarized these studies in a meta-analysis [16]. Ruqhani et al. [17] utilized a large national data set and found that the risk of pulmonary, cardiac, cerebrovascular, and thromboembolic complications was higher in older patients. So for the elderly patients, MVD remains a controversial surgical option, and postoperative morbidities do tend to gradually increase in tandem with an advanced age [17]. So gamma knife or percutaneous procedures might be the first surgical option for the elderly patients with poor fitness.

PBC was first described by Mullan and Lichtor [8] in 1983. Because PBC is a minimally invasive, low-cost, safe, and effective procedure and could be simply performed with the patient under general anesthesia, it has become increasingly popular around the world. It has also been reported to provide longer pain relief than the other two percutaneous procedures and SRS [4]. Several studies $[4,8,17-23]$ had proved the safety and efficacy of PBC. In their 20-year follow-up study of 496 patients, Skirving and Dan [19] reported that the acute pain relief was $99.8 \%$, recurrence rate was $19.2 \%$ within 5 years, 
Table 5 Postoperative complications of PBC series (\%)

\begin{tabular}{|c|c|c|c|c|c|c|c|}
\hline Series & Facial numbness & Masseter muscle weakness & Dysesthesia & Anesthesia dolorosa & Corneal anesthesia & Diplopia & Meningitis \\
\hline Brown et al. & 77 & 16 & 3.5 & 0 & 0 & 0.7 & 5 \\
\hline Skirving et al. & 89 & 3.4 & 3.8 & 0 & 0 & 1.6 & 0 \\
\hline Stomal et al. & $>90$ & 11.9 & 1.7 & 1.7 & 0 & 3.4 & 0 \\
\hline Chen et al. & 100 & 18.8 & a & 0 & 15.6 & 0 & 0 \\
\hline Campos et al. & a & 17.9 & 10.3 & 0 & 2.6 & 2.6 & 0 \\
\hline
\end{tabular}

Not clear

and $31.9 \%$ over a mean length of follow-up of 10.7 years. Baabor and Perez-Limonte [22] reported the outcomes on 206 patients; the initial pain relief was $93 \%$, and the recurrence rate was $15 \%$ after a 3 -year followup. Lichtor and Mullan [23] reported their experience on 100 patients; the successful rate was $97 \%$, and the recurrence rate was $20 \%$ for 5 years. In the present study, we found that the pain relief was immediate in $97.0 \%$ of the patients, with a mean length of follow-up of 40.1 months; $80.9 \%$ of the patients were still pain free. Our efficacy was similar with the published studies. Nine cases had mild recurrence; of these, three cases did not require medication, six cases could adequately be controlled with medication, and most of them were satisfied with the results. PBC was repeated a second time in the two patients who suffered severe recurrence.

As expected preoperatively, numbness and transient masseter muscle weakness were the two most common complications, affecting 66 patients $(97.1 \%)$ and 19 patients $(27.9 \%)$, respectively, in this study. Postoperative complications of published series for PBC are listed in Table 5 [21]. According to the report by Skirving and Dan [19], facial numbness occurred in $89 \%$ of 496 patients, symptomatic dysesthesias in $3.8 \%$, and symptomatic masseter weakness in $3.4 \%$. Abdennebi et al. [24] reported complications including dysesthesia (10.6\% of the 150 patients), transient masticatory weakness (6.6 $\%)$, and diminished corneal reflex (2.6\%). Chen et al. [25] reported that $100 \%$ of the patients experienced facial numbness after $\mathrm{PBC}$, and $18.8 \%$ suffered masticatory weakness. In our study, the rate of masseter muscle weakness was higher than those previously reported [19, $24,25]$, and it might be related to our longer compression time (3-8 min, mean $6.2 \mathrm{~min}$ ). In Skirving and Dan's report [19], the duration of compression was between 2 and $7 \mathrm{~min}$. Baabor and Perez-Limonte [22] reported that the compression time was between 1.3 and $3 \mathrm{~min}$.

One patient in our study suffered diplopia secondary to abducens nerve weakness and recovered within 4 months. Several studies have reported that diplopia was a relatively rare complication [19-23], and all of them recovered within 3-6 months. As it could be seen, all cases of diplopia described in the published studied were transient. It is unlike what happens in radiofrequency rhizotomy, which might cause permanent diplopia [21].

\section{Conclusions}

In this study, the authors reviewed data on a cohort of patient older than 80 years. The PBC procedure has advantages in that it is minimally invasive, safe, effective, and could be performed under general anesthesia. This makes it an optimized choice for elderly patients or physically unstable patients which present some special risks for MVD.

\section{Abbreviations}

PBC: percutaneous balloon compression; MVD: microvascular decompression; SRS: stereotactic radiosurgery; BNI: Barrow Neurological Institute.

\section{Competing interests}

The authors declare that they have no competing interests.

\section{Authors' contribution}

YFD and QG drafted the manuscript. XQD and QD participated in surgical treatment. DBY participated in the design of the study and performed the follow-up. HW helped to sort data. WHY conceived of this study and participated in its design and coordination and helped to draft the manuscript. All authors read and approved the final manuscript.

Received: 29 April 2015 Accepted: 6 July 2015

Published online: 18 September 2015

\section{References}

1. Pollock BE, Stien KJ. Posterior fossa exploration for trigeminal neuralgia patients older than 70 years of age. Neurosurgery. 2011;69:1255-9.

2. Jannetta PJ. Arterial compression of the trigeminal nerve at the pons in patients with trigeminal neuralgia. J Neurosurg. 1967;26:159-62.

3. Li ST, Wang X, Pan Q, Hai J, Liu N, Shen F, et al. Studies on the operative outcomes and mechanisms of microvascular decompression in treating typical and atypical trigeminal neuralgia. Clin J Pain. 2005;21:311-6.

4. Tatli M, Satici O, Kanpolat $Y$, Sindou M. Various surgical modalities for trigeminal neuralgia: literature study of respective long-term outcomes. Aeta Neuraehir (Wien). 2008;150:243-55.

5. Mendoza N, Illingworth RD. Trigeminal neuralgia treated by microvascular decompression: a long-term follow-up study. Br J Neurosurg. 1995;9:13-9.

6. Tan LK, Robinson SN, Chatterjee S. Glycerol versus radiofrequency rhizotomy - a comparison of their efficacy in the treatment of trigeminal neuralgia. Br J Neurosurg. 1995;9:165-9.

7. Little AS, Shetter AG, Shetter ME, Bay C, Rogers CL. Long-term pain response and quality of life in patients with typical trigeminal neuralgia treated with gamma knife stereotactic radiosurgery. Neurosurgery. 2008;63:915-23. discussion 923-924.

8. Mullan S, Lichtor T. Percutaneous microcompression of the trigeminal ganglion for trigeminal neuralgia. J Neurosurg. 1983;59:1007-12.

9. Koopman JS, Dieleman JP, Huygen FJ, de Mos M, Martin CG, Sturkenboom MC. Incidence of facial pain in the general population. Pain. 2009;147:122-7. 
10. Ashkan $\mathrm{K}$, Marsh $\mathrm{H}$. Microvascular decompression for trigeminal neuralgia in the elderly: a review of the safety and efficacy. Neurosurgery. 2004;55:840-50.

11. Günther T, Gerganov VM, Stieglitz L, Ludemann W, Samii A, Samii M. Microvascular decompression for trigeminal neuralgia in the elderly: long-term treatment outcome and comparison with younger patients. Neurosurgery. 2009;65:477-82.

12. Ferroli P, Acerbi F, Tomei M, Tringali G, Franzini A, Broggi G. Advanced age as a contraindication to microvascular decompression for drug-resistant trigeminal neuralgia: evidence of prejudice? Neurol Sci. 2010;31:23-8.

13. Javadpour M, Eldridge PR, Varma TR, Miles JB, Nurmikko TJ. Microvascular decompression for trigeminal neuralgia in patients over 70 years of age. Neurology. 2003;60:520.

14. Sekula RF, Marchan EM, Fletcher LH, Casey KF, Jannetta PJ. Microvascular decompression for trigeminal neuralgia in elderly patients. J Neurosurg. 2008;108:689-91.

15. Yang DB, Wang ZM, Jiang DY, Chen HC. The efficacy and safety of microvascular decompression for idiopathic trigeminal neuralgia in patients older than 65 years. J Craniofac Surg. 2014;25:1393-6.

16. Sekula Jr RF, Frederickson AM, Jannetta PJ, Quigley MR, Aziz KM, Arnone GD. Microvascular decompression for elderly patients with trigeminal neuralgia: a prospective study and systematic review with meta-analysis. Clinical article. J Neurosurg. 2011;114:172-9.

17. Brown JA, McDaniel MD, Weaver MT. Percutaneous trigeminal nerve compression for treatment of trigeminal neuralgia: results in 50 patients. Neurosurg. 1993;32:570-3.

18. Correa CF, Teixeira MJ. Balloon compression of the Gasserian ganglion for the treatment of trigeminal neuralgia. Stereotact Funct Neurosurg. 1998;71:83-9.

19. Skirving DJ, Dan NG. A 20-year review of percutaneous balloon compression of the trigeminal ganglion. J Neurosurg. 2001;94:913-7.

20. Asplund P, Linderoth B, Bergenheim AT. The predictive power of balloon shape and change of sensory functions on outcome of percutaneous balloon compression for trigeminal neuralgia. J Neurosurg. 2010;113:498-507.

21. Du Y, Yang D, Dong X, Du Q, Wang H, Yu W. Percutaneous balloon compression (PBC) of trigeminal ganglion for recurrent trigeminal neuralgia after microvascular decompression (MVD). Ir J Med Sci. 2014; DOI 10.1007/ s11845-014-1163-7.

22. Baabor MG, Perez-Limonte L. Percutaneous balloon compression of the gasserian ganglion for the treatment of trigeminal neuralgia: personal experience of 206 patients. Acta Neurochir Suppl. 2011;108:251-4.

23. Lichtor T, Mullan JF. A 10 year-follow-up review of percutaneous microcompression of the trigeminal ganglion. J Neurosurg. 1990;72:49-54.

24. Abdennebi B, Bouatta F, Chitti M, Bougatene B. Percutaneous balloon compression of the Gasserian ganglion in trigeminal neuralgia. Long-term results in 150 cases. Acta Neurochir (Wien). 1995;136:72-4.

25. Chen JF, Tu PH, Lee ST. Repeated percutaneous balloon compression for recurrent trigeminal neuralgia: a long-term study. World Neurosurg. 2012;77:352-6.

\section{Submit your next manuscript to BioMed Central and take full advantage of:}

- Convenient online submission

- Thorough peer review

- No space constraints or color figure charges

- Immediate publication on acceptance

- Inclusion in PubMed, CAS, Scopus and Google Scholar

- Research which is freely available for redistribution 